\title{
CREACIÓN DE UNA RUTA ARQUEOLÓGICA SUBACUÁTICA EN EL PECIO FENICIO DEL BAJO DE LA CAMPANA Y EL ENTORNO DE ISLA GROSA, LA MANGA, MURCIA
}

\author{
Carlota Pérez-Reverte \\ Universidad de Cádiz \\ https://orcid.org/ 0000-0003-1833-815X \\ Felipe Cerezo Andreo \\ Universidad de Cádiz \\ https://orcid.org/0000-0003-0025-1726
}

\section{RESUMEN}

En los últimos años, la Región de Murcia ha fomentado nuevos modelos turísticos relacionados con la cultura y el mar. Sin embargo, pese a la riqueza de su historia y legado marítimos, no lo ha hecho de forma conjunta. El Mar Menor y La Manga solo han visto potenciado el aspecto marítimo en relación con actividades náuticas, quedando su patrimonio relegado a un segundo plano.

Este trabajo busca reivindicar la riqueza del patrimonio, historia y cultura marítimos asociados a esta zona y mostrar las oportunidades que ofrece su adecuada puesta en valor a través de un caso práctico: la implementación de una ruta arqueológica subacuática en el pecio fenicio del Bajo de la Campana, como parte del Proyecto Isla Grosa.

Palabras clave: Patrimonio cultural subacuático; Cultura Marítima; Arqueología Subacuática; ruta subacuática, Bajo de la Campana; turismo y patrimonio.

\section{A Phoenician Underwater Heritage Trail in Isla Grosa (Murcia), Spain}

\section{ABSTRACT}

In recent years, the Region of Murcia has promoted new tourism models related to heritage and the sea. However, despite the richness of its maritime history and heritage, it has not done so in a complementary manner. The Mar Menor-La Manga area has only boosted the

Fecha de recepción: 13 de febrero de 2019

Fecha de aceptación: 4 de octubre de 2019

* Facultad de Filosofía y Letras. Universidad de Cádiz. Av. Dr. Gómez Ulla, 1. 11003 CÁDIZ (España)E-mail: carlotapreverte@gmail.com,felipe.cerezo@uca.es 
maritime aspect in relation to nautical activities, leaving their heritage relegated to a second place.

This paper seeks to vindicate the importance of the Maritime Heritage, History, and Culture associated with this area and to show the opportunities offered by its proper enhancement through a case study: the implementation of an underwater heritage trail in the Phoenician wreck of the "Bajo de la Campana" as part of the "Isla Grosa" Project.

Keywords: Underwater Cultural Heritage; Underwater Archaeology; Public Archaeology; Underwater Heritage Trail; Bajo de la Campana.

\section{TURISMO CULTURAL, DIFUSIÓN Y PROTECCIÓN DEL PATRIMONIO}

Una de las pruebas más claras de la creciente importancia del turismo cultural en la actualidad es el aumento exponencial de investigaciones, trabajos y proyectos que se ha dado en los últimos años en relación con este tema, que ha llegado a ocupar un espacio destacado en los foros de debate, incluso en campos tan específicos como el de la Arqueología Subacuática. A continuación, y sin pretender hacer una revisión exhaustiva de todos estos trabajos, resaltaremos algunas de las fortalezas y debilidades que presenta este tipo de turismo en relación con la puesta en valor y difusión del patrimonio, y que encontramos de especial interés en el caso de la Región de Murcia; sobre todo, si nos referimos a la zona de La Manga del Mar Menor (Figura 1)

Entre los beneficios derivados del tándem patrimonio-turismo, podemos señalar que revitaliza el interés de los habitantes por su cultura, refuerza la identidad cultural y fortalece los vínculos de la comunidad a través del propio conocimiento de la historia compartida y del reconocimiento por parte del visitante de algunos de sus principales rasgos distintivos (Fuentes; 2015). Por otro lado, este tipo de experiencias pueden potenciar, tanto en el visitante como en la localidad anfitriona, rasgos como la sensibilidad por el cuidado del medio y el patrimonio o la tolerancia y el interés por la diversidad cultural, propiciando oportunidades de intercambio cultural y promoviendo la "comprensión y entendimiento entre los pueblos" (Toselli, 2006).

Otro de los aspectos positivos es el del potencial para el desarrollo a nivel local y regional. Quizá este es uno de los ámbitos más trabajados hoy en día ${ }^{1}$, y son numerosas las iniciativas en este sentido, tanto en la Región de Murcia como a nivel nacional e internacional. De hecho, para algunos autores, el aspecto cultural puede llegar a ser condición sine qua non para hablar de desarrollo: "El desarrollo sostenible no es sólo un concepto económico. El desarrollo o es (...) social y cultural o no es desarrollo. Un auténtico desarrollo encuentra su soporte, su sostenibilidad, en el desarrollo social y en el desarrollo individual de sus ciudadanos" (Iniesta Sanmartín, 2008).

Finalmente, el turismo cultural puede ser un importante aliado a la hora de diversificar la oferta turística, aportar "un valor añadido o de diferenciación en los destinos

1 Un tema ampliamente tratado en trabajos como los de Moragues Cortada (2006), Toselli (2006), Herrero Prieto y Devesa Fernández (2012) o Fuentes (2015). 


\section{Figura 1 \\ PLANO DE SITUACIÓN}

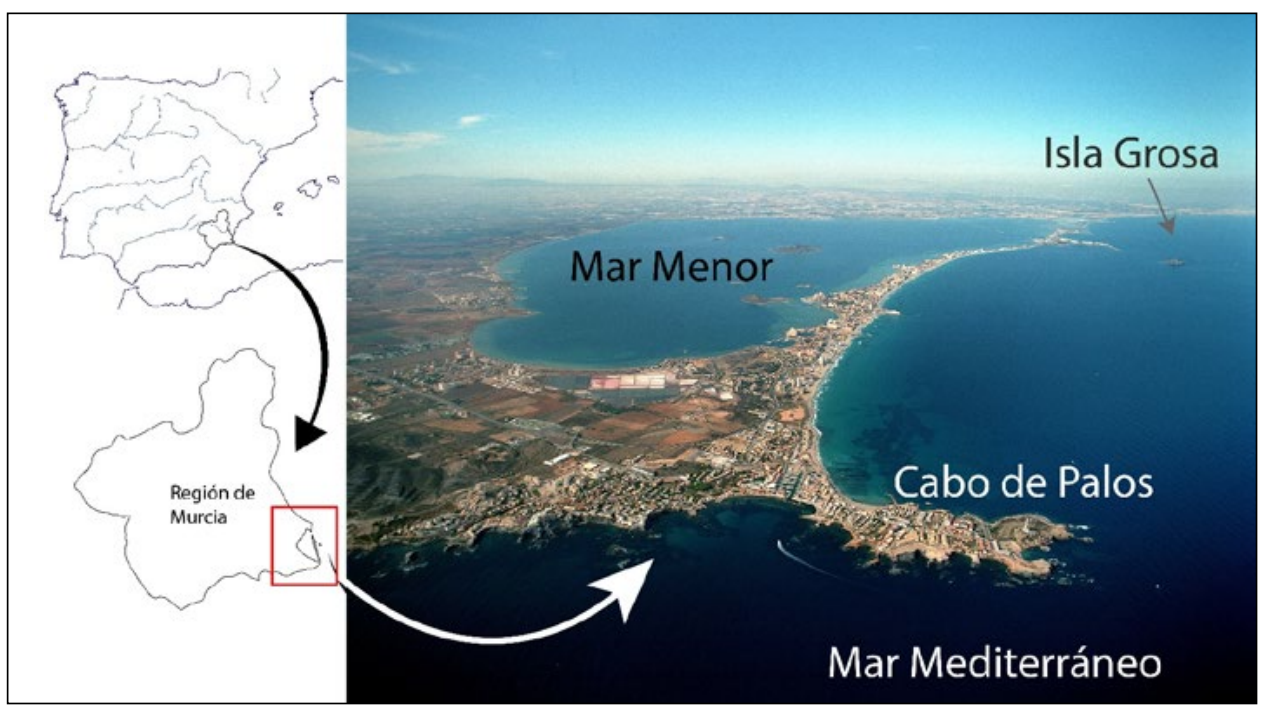

Fotografía original de Estación Náutica Mar Menor: http://www.enmarmenor.com/enmm/

turísticos ya desarrollados o maduros" (Toselli, 2006) y romper con la estacionalidad que caracteriza al modelo basado en el binomio de sol y playa, tan extendido en el Mediterráneo. Para que el turismo cultural cumpla con estas expectativas, es necesario que se den ciertas condiciones como una adecuada planificación, rigurosidad en los elementos interpretativos, cooperación entre los diferentes agentes implicados, respeto y protección de los recursos, etc. En caso contrario, los resultados pueden ser perjudiciales tanto para el visitante como para la comunidad anfitriona y los bienes patrimoniales (que, recordemos, no son regenerables).

Siguiendo este razonamiento, una de las grandes preocupaciones entre los autores está en relación con la potencial masificación, perversión, degradación, alteración o destrucción de los bienes patrimoniales, que pueden llegar a convertirse en simples recursos, reclamos o productos comerciales (Bellido Blanco, 2018). Orduna y Urpí (2010) hacen una interesante síntesis de los principales problemas relacionados con estas malas prácticas, entre los que podemos destacar: banalizar, escenificar o artificializar la cultura local provocando incomprensión, rechazo, marginación o falta de identificación en la comunidad anfitriona; originar un sentimiento de decepción o frustración en el visitante; provocar un proceso de aculturización del destino; crear o perpetuar modelos extractivos (Morgades Cortada, 2006) y alterar el equilibrio social de la comunidad, por citar algunos ejemplos.

Sin embargo, la solución no pasa, en nuestra opinión, por sobreproteger los bienes culturales apartándolos del público (a menos que sea imperativo para su conservación), 
sino por encontrar un equilibrio entre conservación, uso y disfrute (Millán Escriche, 2001), buscando sostenibilidad en todos los aspectos, manteniendo el respeto y protección de los bienes y la comprensión y difusión de sus valores culturales y priorizando su sentido último y su retorno social (Llull Peñalba, 2005; Ballart, 2010). De hecho, tanto si hablamos del patrimonio cultural en general o del subacuático de forma específica, son numerosos los autores que defienden la difusión y el conocimiento del público como una herramienta indispensable para su protección y supervivencia: "solo lo que se conoce se ama y se protege" (Cerezo Andreo, 2012; Bombico et al.,2013; Nieto,2007).

Así, un turismo cultural bien entendido cumple también con una correcta difusión del patrimonio. Un patrimonio que es un derecho (Cerrillos, 2014; Pérez-Prat, 2014) y una difusión que es también una responsabilidad ética, puesto que media entre estos bienes y sociedad, facilitando el diálogo entre ambos y, aún más, actuando como una herramienta de "sensibilización frente a los conceptos de fragilidad, perdurabilidad y pertenencia" (Martín, 2007). Aunque con las siguientes palabras Querol y Martínez Díaz (1996) se refieren a bienes arqueológicos, sin duda pueden aplicarse a los bienes culturales en su conjunto: "Lo verdaderamente importante sobre el Patrimonio Arqueológico, lo que en realidad lo hace, es su incidencia social. O la sociedad participa y disfruta de estos bienes o ni siquiera podrán denominarse Patrimonio; sin embargo, es precisamente la ausencia de una incidencia social positiva el mayor de los problemas que afectan al Patrimonio Arqueológico”.

Para concluir, la difusión favorece la conservación y la gestión a largo plazo porque el valor que otorga la sociedad a estos bienes condiciona directamente las herramientas para gestionarlos (Pérez-Reverte y Cerezo Andreo, 2019). Aspectos como los recursos económicos que se dedican, las políticas culturales o la legislación, dependen en gran medida del "valor que la sociedad atribuye a estos recursos y a los esfuerzos de preservación relacionados con ellos" (Catsambis y Morrand, 2015; sobre la misma idea en Nieto, 2007).

Todas estas cuestiones cobran una especial importancia cuando hablamos del patrimonio cultural subacuático, puesto que se enmarca en un medio y unas condiciones que conllevan importantes limitaciones. Por un lado, es menos visible y accesible, lo que ha propiciado un desfase respecto al ámbito terrestre en todos los aspectos. Y a este desfase, a su propia naturaleza y a la relativa juventud de la ciencia que lo investiga, la Arqueología Subacuática, se une un hándicap añadido: la aureola de fascinación y misterio que rodea al mundo submarino. Por desgracia, y aunque en los últimos diez años la situación del patrimonio cultural subacuático ha cambiado y se ha incrementado el nivel de investigación y difusión, de preocupación, implicación y demanda social, su imagen aún dista de dibujarse con propiedad en la mente de la sociedad y muchos de sus recursos están en peligro porque, como se verá, se están explotando actualmente sin ofrecer la información y educación necesaria ni las garantías suficientes para su conservación. Y es que hay recursos patrimoniales especialmente frágiles que requieren sensibilidad y sensibilización para su uso y disfrute.

\section{MURCIA: TURISMO, PATRIMONIO Y MAR}

Si bien es cierto que el Mar Mediterráneo es uno de los destinos más importantes del mundo, también lo es que tanto el modelo turístico masivo que se implanta en sus costas a partir de los años 50, como el residencial que cobra importancia a partir de los 
años 90 (Mazón y Aledo, 2005; Espejo y Marín, 2011), articulados ambos en torno al binomio sol y playa, se consideran en la actualidad desfasados, insuficientes o, incluso, agotados o perjudiciales.

Esto se debe a varios motivos. Por un lado, su marcada estacionalidad vinculada, lógicamente, al clima. Por otro, se trata de modelos que han empobrecido considerablemente la salud del Mediterráneo y de nuestras costas (Morales Yago, 2013); han aparecido nuevos destinos en el mapa (jóvenes, menos desgastados y competitivos) y las circunstancias y preferencias del visitante también han variado. El nuevo turista ha visto mejorados sus derechos laborales (Marcos Pérez y González Velasco, 2003); vive en un mundo de prisas e inmediatez (Millán Escriche, 2001) y busca desconectar; la publicidad y las redes sociales le venden felicidad instantánea, vive en la era de la autorrealización, del "porque yo lo valgo" y de la hipermovilidad (Mazón y Aledo, 2005). Cada vez se interesa más en actividades dinámicas que van más allá del descanso, relacionadas con la nueva forma de entender el ocio; actividades gratificantes, enriquecedoras, formativas, participativas y con un creciente nivel de individualización (Salvá Tomás, 1998). En este sentido, numerosos autores aluden a términos como actitud interior, vivencia, aventura o experiencia. Aunque otros nos recuerdan que, pese a las apariencias, una parte no desdeñable de los visitantes aborda estas prácticas desde una cierta superficialidad (Orduna y Urpí, 2010).

Todo ello ha llevado a buscar nuevas alternativas con el objetivo de diferenciarse, diversificar la oferta, complementarla, y romper la estacionalidad. Así, surgen nuevos modelos basados en "la valorización del patrimonio natural", "la revalorización de la cultura como recurso turístico", "el mar como elemento de actividades de ocio" o "la valorización del cuerpo humano", a nivel físico y espiritual (Salvá Tomás, 1998; Cebrián Abellán, 2004).

Murcia es un claro ejemplo de la convivencia del antiguo modelo (masificado, residencial, de sol y playa) y estas nuevas tendencias (Millán Escriche, 2010). La riqueza patrimonial y natural de la Región ha servido para dar cabida a numerosas iniciativas públicas $^{2}$ y privadas orientadas a poner en valor estos recursos. La página web de Costa Cálida-Murcia Turística incluye una sección de folletos ${ }^{3}$, muy ilustrativa a este respecto, que agrupa muchas de estas actividades por áreas temáticas y público objetivo: naturaleza, golf, enotursimo, cicloturismo, buceo, actividades náuticas, turismo escolar, familiar o senior, etc.

Pese a que no hay un folleto específico sobre turismo cultural o sobre la Historia de la Región, desde la administración regional se han desarrollado diversos proyectos relacionados. Por ejemplo, Lorca, taller del tiempo ${ }^{4}$; Cartagena, Puerto de Culturas ${ }^{5}$ o Murcia Sacra y el año jubilar ${ }^{6}$, a los que se suman otros como la recién creada Ruta literaria de Cartagena ${ }^{7}$ o la puesta en valor de la artesanía regional a través de la crea-

\footnotetext{
2 Ya desde finales de los 90, se contempla la necesidad de esta reorientación en el Plan de Reactivación Económica de la Región de Murcia (Cebrián Abellán, 2004:15)

3 https://www.murciaturistica.es/es/folletos/

4 http://lorcatallerdeltiempo.es/bensakar/inicio

5 https:/www.cartagenapuertodeculturas.com/

6 https://www.murciaturistica.es/camino-de-la-cruz/inicio/

7 http://www.cocin-cartagena.es/cartagena/ruta-literaria-de-cartagena/
} 
ción de centros de comercio centralizados, la implantación de rutas y otras propuestas por parte de asociaciones locales.

El mar, otro de los grandes atractivos de Murcia, sí se ve ampliamente reflejado como reclamo turístico en Web oficial y también en otras iniciativas como la creación de la Estación Náutica Mar Menor ${ }^{8}$. Una marca que busca la diferenciación como destino turístico de calidad para la práctica de deportes náuticos y que ofrece, organiza y comercializa, servicios integrados (alojamientos, actividades deportivas, actividades complementarias relacionadas con el entorno, etc.).

El Mar Menor y, más concretamente La Manga, es un destino y un reclamo de primer orden en la Región. Sin embargo, o quizá por eso, se trata de una de las zonas que más ha sufrido los efectos de una mala praxis, no solo turística sino de gestión general. Los problemas medioambientales y la destrucción de ecosistemas son una realidad tangible en este entorno privilegiado que se mantuvo prácticamente virgen hasta los años 60 . Hasta tal punto es así, que la prensa local y nacional ha reflejado esta situación con titulares como: "El Mar Menor ya es un Mar Muerto"9 "Medusas, plancton y cemento: el Mar Menor está en la UVI"10, "Cerrada al baño la Playa del Espejo de los Alcázares por exceso de aguas fecales"11 o "El caballito de mar podría terminar desapareciendo del Mar Menor"12. Una "publicidad" que, lógicamente, afecta al visitante a la hora de elegir destino y una situación que crea malestar entre la población local ante el resentimiento de sus recursos naturales, sociales, identitarios, turísticos y económicos ${ }^{13}$.

Entre las principales cuestiones relacionados con la destrucción de ecosistemas y problemas medioambientales, Morales Yago (2013) cita las siguientes: pérdida de dunas y reducción de playas, alteraciones resultado de la puesta en marcha de playas artificiales, destrucción de zonas lacustres y pérdida de biodiversidad, dificultades de aireación en edificaciones y problemas derivados de la producción de deshechos tanto en tierra como en el mar. También señala una nula conservación del escaso patrimonio de arqueología industrial y etnografía local.

Aunque encontramos esta última afirmación absolutamente acertada, lo cierto es que el patrimonio cultural de la Región y de esta zona en concreto es mucho más rico y abundante de lo que frecuentemente se piensa y va mucho más allá de la Arqueología Industrial y la Etnografía.

\subsection{Historia y Cultura Marítimas de la Región de Murcia}

El término "Cultura Marítima” en la Región de Murcia puede parecer extraño. Si bien existen diversas iniciativas que buscan poner en valor la tradición y cultura marítimas propias de la Región, muchas de éstas quedan a veces en la anécdota y no profun-

8 http://www.enmarmenor.com/enmm/

9 El Español, 21/08/2016

10 El Mundo, 52/07/2017

11 La Opinión de Murcia, 13/08/2017

1220 Minutos, 07/01/2018

13 Si bien es cierto que se han tomado medidas para mejorar la "salud" de las aguas del Mar Menor, todos estos daños siguen siendo claramente visibles. 
dizan en la amplia evidencia patrimonial, tanto material como inmaterial ${ }^{14}$, vinculada al mar y sus recursos.

La región es tremendamente variada en sus tipos y categorías patrimoniales, producto de una microregionalización geográfica que ha propiciado paisajes, poblamientos y tradiciones culturales diversas. Una de ellas es la que podríamos relacionar con la zona litoral del Sureste ibérico en un sentido amplio. Al menos desde el Paleolítico Superior se establecieron en cuevas y abrigos del litoral murciano grupos que utilizaban recursos marinos (Hoffmann et al., 2018; Martínez Andreu, 2003; Montes, 1991). En periodos posteriores parece evidente la conectividad marítima del litoral, con asentamientos costeros del Bronce como, por ejemplo, los yacimientos de Monte Blanco o Cala del Pino, situados en la misma Manga del Mar Menor. Los recursos marinos principalmente vinculados a la pesca, algas y otros elementos, también fueron clave en el sustento económico de las primeras colonizaciones fenicias o grupos sociales autóctonos como el situado en Los Nietos, en la margen suroeste del Mar Menor (García Cano, 1996). Por no hablar de aquellos sitios de mayor repercusión científica y turística como son la propia Cartagena, la Villa Romana del Paturro (Portman) o los yacimientos fenicios y púnicos de la costa de Mazarrón, destacando entre ellos el pecio de época fenicia de Playa de la Isla (Negueruela et al., 1995).

En este entorno privilegiado, tanto desde el punto de vista geoestratégico (confluencia de diferentes rutas de navegación), como en cuanto a la abundancia de recursos marinos y mineros, se documentan actualmente cerca de 173 yacimientos inventariados en la Carta Arqueológica de la Región de Murcia. Su cronología es muy diversa. Pueden encontrarse yacimientos prehistóricos como la Cueva de los Mejillones, asentamientos ibéricos, púnicos o romanos; todos ellos de diferente categoría, aunque abundan los relacionados con la explotación agrícola y minera. Uno de los periodos tal vez menos trabajados, pero de gran interés en esta zona, es el correspondiente al periodo medieval en sus dos fases, tanto islámica como castellana, donde los pleitos por el control de las encañizadas y la pesca en la laguna dan fe de su importancia de forma clara (Munuera Navarro, 2010; Torres Fontes, 1987). Destaca aquí también la riqueza de un patrimonio inmaterial y paisajístico de fuerte influencia marítima, como es el de las artes de pesca de las encañizadas, las salinas, o el excepcional caso del Monte Miral y San Ginés de la Jara. Mención aparte merecen las casas torre, construcciones características de la defensa y protección de las poblaciones litorales durante el s. XVI y XVII, así como las torres y atalayas de vigilancia costera. En definitiva, esta zona atesora un patrimonio que narra la historia de una sociedad vinculada al mar y que durante diferentes periodos tuvo una relación simbiótica con el mismo. A todo ello, recordemos añadir el rico patrimonio industrial que jalona las riberas del Mar Menor ya mencionado por Morales Yago (2013).

La riqueza patrimonial marítima de La Manga - Mar Menor es, como se ha visto, innegable, pero además viene complementada por una categoría patrimonial única vinculada a la cultura marítima: los yacimientos sumergidos. De los 173 yacimientos citados

14 Sobre el patrimonio inmaterial de la Región, su importancia, relación con la cultura material y potencial para el desarrollo y la educación, recomendamos el artículo de Lema Campillo (2008) La gestión del patrimonio inmaterial en sociedades complejas en el siglo XXI. Propuestas para implementar políticas de actuación en la Región de Murcia, España. 
anteriormente, 30 son de tipo subacuático (Más García, 1985; Pinedo Reyes,1996). Y hablamos solo de los datos conocidos e inventariados dentro de la Carta Arqueológica de la Región de Murcia, quedando fuera numerosos elementos patrimoniales de tipo industrial o contemporáneo, como el Sirio, el Naranjito y otros pecios de las guerras mundiales. La importancia de estos yacimientos como cultura material y recurso patrimonial, viene además complementada con una impronta clave en el imaginario colectivo, en aquello que llamamos patrimonio inmaterial o cognitivo, muy vinculado a los eventos de naufragio dramáticos, como el del Sirio, que veremos más adelante.

\subsection{Turismo de pecios}

El desarrollo del buceo autónomo ha fomentado un aumento exponencial en el buceo deportivo en los últimos años (Staniforth, 2010). Desde 1967, solo la organización PADI (siglas en inglés para "Asociación Profesional de Instructores de Buceo") ha concedido más de 24 millones de licencias en todo el mundo ${ }^{15}$. El volumen del mercado de inmersión se cuantificó en 2016 en torno a 7 millones de buceadores en el mundo y en 2,5 - 3 millones a nivel europeo, con una demanda en crecimiento, en torno al 5\% anual. ${ }^{16}$.

Como ya hemos mencionado, dentro del polo estratégico de interés empresarial que supone el turismo en la Región de Murcia, destacan las propuestas vinculadas a actividades náuticas y subacuáticas, dada la calidad de sus aguas y las excelentes condiciones de visibilidad y temperatura, que permiten bucear todo el año.

El buceador medio está constantemente a la búsqueda de nuevas experiencias, retos y oportunidades y algunos de los principales incentivos a la hora de elegir destino son el entorno, el nivel técnico de la inmersión o la variedad que pueden ofrecer experiencias diferentes como las inmersiones nocturnas, el buceo en cuevas o en el buceo en pecios ${ }^{17}$. En este sentido, uno de los grandes reclamos son los pecios históricos ${ }^{18}$. El caso de la Región de Murcia no es una excepción y los pecios están presentes no solo en la oferta de los centros de buceo sino, también, en la promoción turística general.

$\mathrm{Si}$ "nos sumergimos" en la página oficial de turismo de la Región de Murcia, y nos interesamos por actividades relacionadas con el mar y el buceo, encontraremos numerosas alusiones a los pecios históricos, por ejemplo: "El mejor destino de buceo del Mediterráneo: La riqueza de sus fondos marinos, tanto por la variedad de su fauna y belleza de su flora, como por los numerosos pecios históricos que albergan, convierten a la zona de Cabo Palos e Islas Hormigas (Reserva Marina) e Isla Grosa, Cartagena, La Azohía y Cabo Tiñoso (Reserva Marina), Mazarrón y a Águilas, en lugares excepcionales para bucear todo el año"; o, en la ruta del Mar Menor y La Manga, "Para los amantes del submari-

15 Datos ofrecidos por PADI en https:/www.padi.com/sites/default/files/documents/about-padi/statistics/ PADI_2016_WW_Statistics.pdf

16 Estudio de oportunidades de negocio en el sector de actividades subacuáticas en la Región de Murcia. CEEIC, 2016.

17 Dejando de lado las discusiones terminológicas propias de cada disciplina, podemos generalizar diciendo que un pecio es el resto hundido de una nave (aeronaves incluidas).

18 Generalizaremos de nuevo para sintetizar, definiendo los pecios históricos como aquellos que, debido a su cronología, historia, excepcionalidad u otras circunstancias, revisten un interés histórico. 
nismo, templadas aguas con fondos de abundante fauna y flora (...) o dejarse cautivar por restos de barcos hundidos."

También se utilizan los pecios como reclamo en la ya mencionada sección de folletos: el folleto general alude a "los numerosos pecios que guardan grandes historias", el de "Murcia Slow" presenta a toda página una preciosa foto de una inmersión en el pecio "Naranjito" y, por supuesto, el folleto dedicado a buceo hace amplia mención a esta cuestión que ocupa, incluso, su portada.

El buceo en pecios es una actividad muy popular tanto dentro como fuera de nuestro país y poderosamente atractiva. A la espectacularidad de los restos se une la belleza del entorno, la riqueza de la fauna y la posible dificultad añadida en función de la profundidad y la situación, ya que los barcos con frecuencia naufragan en zonas con condiciones adversas. Por este motivo, el buceo en pecios se considera una especialidad en los programas oficiales de buceo y se ofrecen cursos que aportan los recursos técnicos necesarios. Por desgracia, no siempre incluyen los educativos.

\subsubsection{El caso del Sirio}

Cabo de Palos es considerado uno de los diez destinos de buceo más interesantes del mundo ${ }^{19}$ no solo por la mencionada calidad de sus aguas y su riqueza natural, sino también por los numerosos barcos hundidos que descansan sobre sus fondos. Éste es para muchos uno de sus principales atractivos ya que no solo tiene pecios a distintas profundidades, sino que, además, muchos de ellos están concentrados en una misma zona. Esto, unido a la existencia de la Reserva Marina, ha convertido al buceo en una industria muy activa en este área (CEEIC, 2006). No en vano esta localidad de unos 1000 habitantes concentra en la bocana de su puerto casi una decena de centros de buceo.

Cabo de Palos (y su entorno) es un auténtico cementerio de barcos. Quizá uno de los más importantes del Mediterráneo, con al menos medio centenar de naufragios de barcos modernos (y muchos otros de embarcaciones antiguas). Algunos de estos pecios son el resultado de hundimientos planificados para la creación de arrecifes, otros son bajas resultado de maniobras durante la Primera y la Segunda Guerra Mundial y otros tantos, fruto de accidentes contra la peligrosa costa. Muchos de ellos son testigos de nuestra Historia y testimonio de terribles tragedias.

Este es el caso, por ejemplo, del que ha sido llamado "El Titanic de Cabo de Palos" o "El Titanic del Mediterráneo": El SS. Sirio, naufragado en estas costas en agosto de 1906 mientras realizaba la ruta transoceánica entre Italia y Argentina. Un buque de 115 metros de eslora, que había salido de Génova con una carga de pasajeros, inmigrantes en su mayoría, que viajaban a América en busca de nuevas oportunidades. Aunque la población de Cabo de Palos se volcó en el rescate de forma encomiable, la rapidez del hundimiento y la incapacidad de la tripulación, que abandonó a los pasajeros a su suerte, supusieron la pérdida de más de 250 vidas $^{20}$.

19 https://www.nationalgeographic.com.es/viajes/los-mejores-lugares-para-bucear_10011/2

20 Es difícil precisar con exactitud la cantidad de víctimas puesto que era frecuente que este tipo de barcos hiciera paradas no programadas para recoger a pasajeros ilegales que, por tanto, no figuraban en el registro. 
Pese a la innegable importancia histórica de esta catástrofe; pese al respeto que, sin duda, merece el barco que fue la tumba de más de 200 personas, el Sirio estuvo sometido a un duro saqueo ${ }^{21}$ por parte de los buceadores recreativos durante muchos años. La creación de la Reserva Marina en 1995 mejoró la situación de este pecio, al quedar incluido en el espacio que comprende. Respecto a su protección, aunque España ratificó en 2005 la "Convención de la UNESCO para la Protección del Patrimonio Cultural Subacuático de 2001”, hasta 2006 este pecio no entraría en esta categoría. Y es que, para la UNESCO: "El patrimonio cultural subacuático comprende todas las huellas de la existencia humana que poseen un carácter cultural, arqueológico o histórico; y hayan estado bajo las aguas, tanto marítimas como fluviales y lacustres, parcial o totalmente, de forma periódica o continua por lo menos durante cien años."

Trazar líneas como la de los cien años es importante a la hora de legislar, y necesario en el ámbito penal. Sin embargo, si esperamos al "cumpleaños" de este tipo de pecios, nos arriesgamos a encontrarlos muy degradados cuando lleguen las herramientas legales para su protección. No es difícil encontrar en internet objetos extraídos del Sirio: desde platos o bisagras hasta, por ejemplo, un ojo de buey ${ }^{22}$. Piezas que, a pesar de que esta embarcación se reconoce hoy en día como patrimonio cultural subacuático, no se encuentran en ningún museo institucional.

Es necesario tomar conciencia de que muchos de los llamados pecios históricos se están explotando económicamente y como recurso turístico no solo en la Región de Murcia sino en general en nuestro país, sin la necesaria investigación previa, sin la posibilidad de un control efectivo, sin una adecuada puesta en valor, y sin respetar sus valores patrimoniales. Pese a que el grado de concienciación de los buceadores deportivos es cada vez mayor, y que hay centros de buceo que trabajan de una forma extremadamente respetuosa en torno a este tipo de buceo, en otros casos no se dan estas condiciones con la consiguiente pérdida y degradación de fragmentos de nuestra Historia. La sensibilización de los buceadores y la educación de la sociedad en general son las mejores herramientas para prevenir este tipo de pérdidas, mientras muchos otros pecios esperan a que llegue su "cumpleaños" o a recibir atención por parte de las instituciones competentes.

\section{CONSERVACIÓN IN SITU Y PUESTA EN VALOR DEL PATRIMONIO CUL- TURAL SUBACUÁTICO}

Desde la Arqueología Subacuática y siguiendo las directrices de la mencionada Convención de la UNESCO de 2001, cada vez cobra mayor protagonismo la idea de la conservación in situ del patrimonio cultural subacuático; es decir, en el propio yacimiento. Por un lado, los materiales sumergidos alcanzan un delicado equilibrio con el medio que les proporciona estabilidad. Este equilibrio se altera al extraer las piezas, lo que aumenta su curva de degradación y requiere la aplicación de tratamientos de conservación que, con frecuencia, son largos y costosos (Fernández Ibáñez y Palacio Ramos, 2003; Sierra,

21 No es nuestra intención culpabilizar a los buceadores o los centros, ya que entonces la sensibilización era menor, pero precisamente por este motivo es tan importante este caso que ejemplifica muy bien las consecuencias de una sensibilización deficiente o inexistente.

22 https://www.nationalgeographic.com.es/mundo-ng/actualidad/sirio-titanic-del-mediterraneo_11980/6 
2003; Khakzad y Van Balen, 2012). Por otro, la conservación in situ preserva los materiales en su contexto original. Tras una excavación, los materiales se conservan, restauran y exponen, pero, salvo casos excepcionales, rara vez se exponen como conjunto de modo que, para el visitante, el contexto que ofrecía el yacimiento y la relación entre las piezas se diluye en favor de otras características (Scott-Ireton, 2007; Nieto, 2007; Maarveled et al., 2013). Finalmente, la conservación in situ puede dificultar el acceso directo de una parte de la población al patrimonio (no así el indirecto, gracias a las nuevas tecnologías), pero, en muchos casos, éste puede ser también disfrutado y valorizado, demostrando gran potencial a la hora de educar y concienciar al público sobre la fragilidad e importancia del patrimonio cultural subacuático. Así, cada vez son más abundantes los proyectos y experiencias relacionados con este tipo de puesta en valor. Proyectos y experiencias que se vienen realizando desde los años 80 y cuya fortaleza radica en facilitar, mediante una interpretación arqueológica, el acceso del público al yacimiento subacuático en su contexto sumergido (Pérez-Reverte y Cerezo Andreo, 2019).

Entre los ejemplos más conocidos podemos citar el parque vinculado a la Batalla Naval de Santiago de Cuba (González Díaz, 2017), el parque marítimo histórico del pecio Kronprins Gustav Adolf (Finlandia) ${ }^{23}$, el antiguo puerto de Caesarea (Israel), la ciudad de Baia (Davidde, 2002; Stefanile, 2012) o Santa María di Castellabate en Italia (Abatino,1985; Aguizza, 2012), Cayos de Florida (Scott-Ireton, 2006), los "pecios enjaulados" de Croa$\mathrm{cia}^{24}$ o la ruta de la batalla de Saipan en las Islas Marianas (McKinnon y Carrell,2011). En nuestro país también se han desarrollado iniciativas de este tipo, entre las que sin duda destaca el pecio romano Bou Ferrer en Villajoyosa ${ }^{25}$, y que incluyen desde el uso de réplicas (casos de Ampurias, Nieto, 2007, o Cala Cativa) hasta las visitas puntuales a yacimientos en proceso de excavación como, por ejemplo, las que se desarrollaron entre 2007 y 2011 en el Bajo de la Campana (Murcia) o las que realiza periódicamente la FECDAS, en colaboración con el Centro de Arqueología Subacuática de Cataluña (Aguilar, 2011).

\section{CREACIÓN DE UNA RUTA ARQUEOLÓGICA SUBACUÁTICA EN EL YACI- MIENTO FENICIO DEL BAJO DE LA CAMPANA}

Teniendo presentes estas experiencias y las reflexiones recogidas previamente, el Proyecto Isla Grosa (iniciativa de la Asociación de Amigos del Museo Nacional de Arqueología Subacuática, ARQVA, y la empresa ARQUEOMAR), se lanzó en un entorno privilegiado, como un proyecto piloto que buscaba la puesta en valor del patrimonio cultural subacuático de la zona, la participación y el retorno social, la implicación directa de los centros de buceo de la Región, la sensibilización de los buceadores recreativos y su educación en las directrices de buceo responsable en entornos patrimoniales (PérezReverte y Cerezo Andreo, 2019).

23 https://www.museovirasto.fi/en/cultural-environment/archaeological-cultural-heritage/underwater-cultural-heritage-in-finland/helsingin-hylkypuisto

24 http://icua.hr/images/stories/publikacije/Exploring_Underwater_Heritage_in_Croatia.pdf

25 http://www.bouferrer.org/ 
El proyecto abarcaba tres ámbitos que se retroalimentaban entre sí: un proyecto de investigación de Arqueología Subacuática, la creación de un "yacimiento escuela" dentro de ese marco de investigación y el desarrollo de una ruta subacuática.

\subsection{Estudio previo de público objetivo}

Ante la falta general de estudios de público relacionados con el perfil de los buceadores en general y con el fin de evaluar las carencias formativas y adaptar las herramientas educativas en el trabajo con este colectivo, se realizó un análisis de este perfil a través de una serie de encuestas en los centros de buceo de la Región. Se diseñó una encuesta estructurada que se realizó de forma presencial entre el público de los centros de buceo del área de intervención, compuesta por una serie de preguntas de carácter cuantitativo y otras de tipo cualitativo. Las primeras buscaban obtener información estadística sobre el origen de los visitantes, nivel y hábitos en cuanto a la práctica del buceo (como la frecuencia de buceo en pecios), edad y cuestiones relativas a la identificación de los distintos segmentos de público por edad, sexto, etc. Mientras, la segunda parte buscaba, mediante una serie de preguntas directas combinadas con preguntas de control de respuesta abierta ${ }^{26}$, evaluar el conocimiento previo que los potenciales visitantes tenían sobre el patrimonio cultural subacuático, la arqueología subacuática, la conservación y amenazas del patrimonio, etc.. Las encuestas se realizaron con carácter previo a la actividad durante los periodos de máxima afluencia a los centros de buceo (Navidad y Semana Santa). Las preguntas se plantearon de forma correlativa con el objetivo de comprender mejor las variables de estudio que se pretendían analizar, con el fin de obtener un perfil medio de buceador y su grado de sensibilización. De esta manera, podríamos evaluar las áreas de mejora para así diseñar de forma acertada las acciones encaminadas a cumplir con nuestros objetivos de educación patrimonial. Es decir, dependiendo de la experiencia en buceo o del grado de conocimiento del buceador, deberíamos de plantear una actividad interpretativa más o menos exigente con el visitante y con el propio yacimiento.

En esta encuesta participaron 200 buceadores de diferentes edades, sexo y procedencia (figuras 2 y 3 ), con los siguientes resultados representados en gráficas elaboradas a través de Excel.

Como se puede ver en la figura 3 , en torno a un $20 \%$ de los encuestados residía de forma permanente en el extranjero. Respecto a los buceadores procedentes del territorio nacional, en la misma figura se pueden observar las comunidades con una presencia del $5 \%$ o superior: todas ellas ribereñas del Mediterráneo, con la excepción de la Comunidad de Madrid que destaca claramente sobre las demás. En "Otras Comunidades" se han agrupado aquellas con una presencia inferior al 5\% como La Rioja o Castilla y León, con un 1\% cada una.

26 Por ejemplo, se preguntó a los encuestados si consideraban que habían recibido una formación muy alta, media, baja o casi inexistente en cuanto a patrimonio subacuático. A continuación, se realizaban una serie de preguntas como: ¿es legal bucear en una zona con restos arqueológicos? o ¿A quién debo informar en caso de hallazgo casual? De esta manera, podíamos evaluar no solo las carencias formativas de los buceadores sino su propia percepción en cuanto a su conocimiento. 


\section{Figura 2}

\section{EDAD (A) Y SEXO (B) DE LOS BUCEADORES}

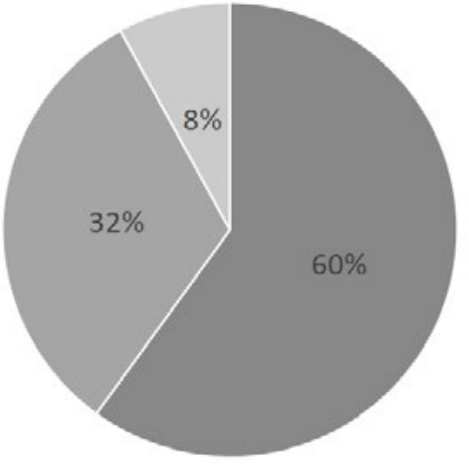

A

m Entre 18 y 35 años = Entre 35 y 50 años

in Mayor de 50 años

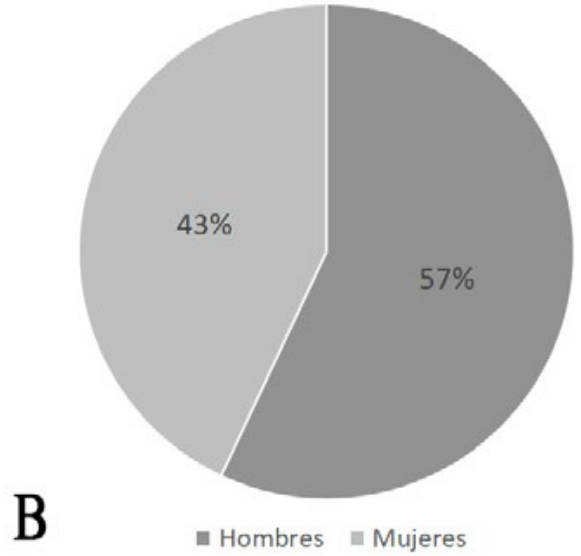

Figura 3

PROCEDENCIA DE LOS BUCEADORES

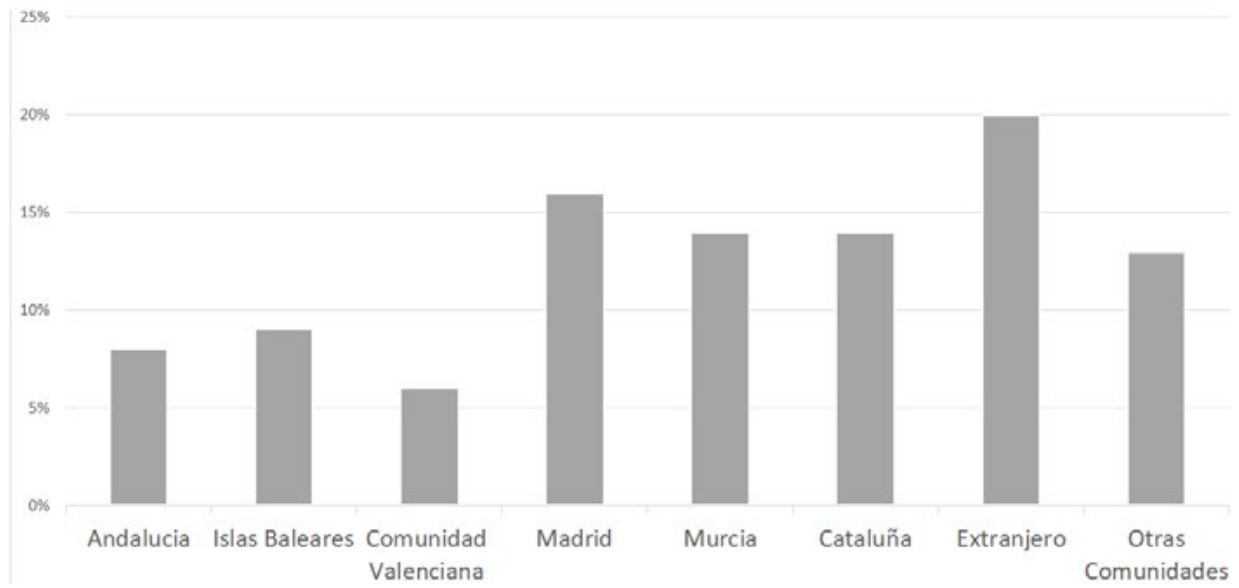

Fuente: Elaboración propia.

Con el fin de comprobar si un mayor conocimiento en técnicas de buceo va acompañado de una mejor formación y mayor sensibilización patrimonial, también se recogieron datos respecto a la titulación y hábitos de buceo de los encuestados.

Respecto a la titulación (figura 4A), la más extendida entre los buceadores era el Advance Open Water Diver PADI o dos estrellas FEDAS, equivalente a un nivel inter- 
medio en buceo recreativo. A continuación, con un $23 \% 27$ la de divemaster o superior; es decir, monitores o instructores de buceo que ya pueden operar a un nivel profesional. El buceo técnico, que es un tipo de buceo recreativo, pero con un nivel creciente de dificultad y especialización, alcanzaba el $18 \%$ entre los encuestados, y un $16 \%$ de ellos tenía el Open Water Diver de PADI o era buceador una estrella de FEDAS, que se considera el nivel inicial en buceo recreativo. Un 3\% de los encuestados eran pareja, amigos o familiares de los buceadores y los acompañaban a realizar la inmersión, pero se quedaban en la superficie buceando con tubo (snorkel).

En cuanto al número de inmersiones anuales (fig.4B), un 20\% de los buceadores hacía inmersiones menos de una vez al mes de media. Pese a que se registró que un $30 \%$ hacía más de 50 inmersiones al año, hay que considerar que un $23 \%$ de los encuestado tenía un título que le permitía ejercer de forma profesional, por lo que es normal encontrar un alto número de inmersiones en este grupo.

\section{Figura 4 \\ TITULACIÓN (A) Y NÚMERO DE INMERSIONES ANULAES (B)}
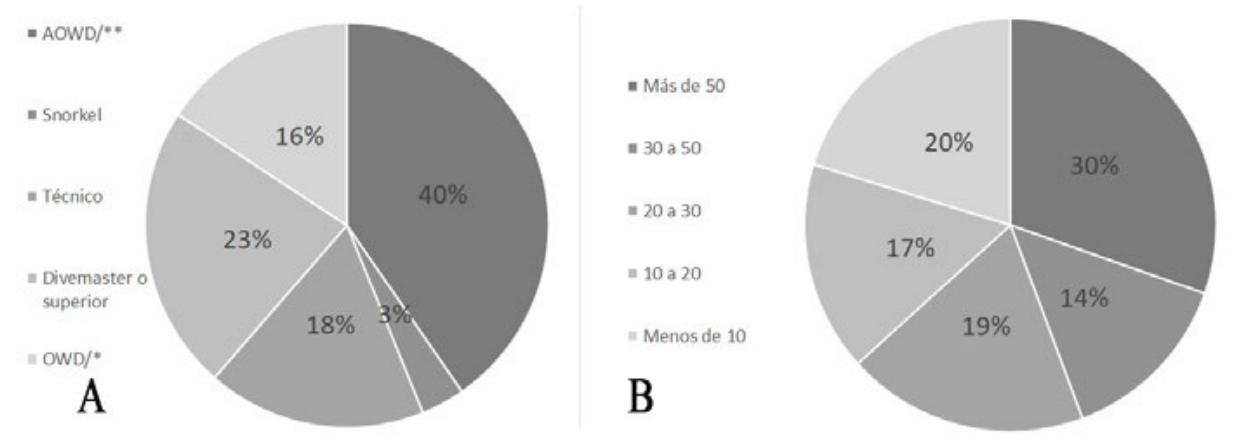

Fuente: Elaboración propia.

Un 91\% de buceadores mostró interés en la Arqueología Subacuática, pese a que más de la mitad no había recibido ningún tipo de formación relacionada con esta disciplina o con el patrimonio cultural subacuático (figura 5).

Aunque un $72 \%$ de los buceadores manifestaba mucho interés en la Arqueología Subacuática y el patrimonio, un 55\% había recibido poca o ninguna información relacionada y solo un $12 \%$ una formación muy completa. O esa era su percepción. La encuesta incluía una serie de preguntas de control relacionadas con el patrimonio y la normativa básica de buceo responsable. De acuerdo con estas preguntas, un $36 \%$ de los encuestados no sabía qué es el patrimonio cultural subacuático, solo un $11 \%$ conocía la legislación más básica y un $90 \%$ no sabía cómo informar de un hallazgo casual.

27 El porcentaje es tan elevado porque también encuestamos al personal de los centros de buceo con el fin de evaluar sus conocimientos sobre patrimonio y prácticas de buceo responsable. 


\section{Figura 5 \\ INTERÉS (A) E INFORMACIÓN RECIBIDA (B) SOBRE ARQUEOLOGÍA SUB- ACUÁTICA Y PATRIMONIO CULTURAL SUBACUÁTICO}
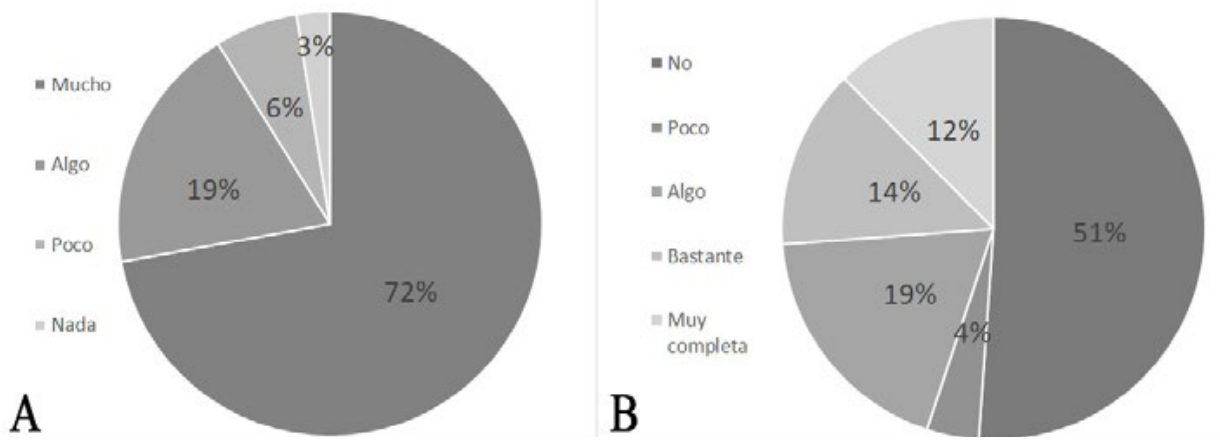

Fuente: Elaboración propia.

Que los buceadores sepan cómo y a quién trasladar este tipo de información es fundamental para la preservación del patrimonio. El mar es un entorno dinámico con condiciones variables, por lo que los restos arqueológicos pueden quedar a la vista o enterrados, dependiendo del momento y las circunstancias. Dado que es imposible monitorear todo el fondo marino en tiempo real, si un buceador encuentra de forma casual una serie de restos es fundamental que esta información llegue a los arqueólogos a través de las instituciones competentes. Ellos podrán establecer si se trata de un nuevo descubrimiento, y lo incluirán en la carta arqueológica, o de un yacimiento conocido, en cuyo caso la información sigue teniendo importancia de cara a monitorizar posibles riesgos o nivel de degradación de los materiales.

Los buceadores están expuestos constantemente a la posibilidad de encontrarse con restos arqueológicos o de interés histórico. El desconocimiento de las normas éticas de buceo $^{28}$, la falta de formación específica y la ausencia de una relación positiva entre los buceadores y el patrimonio, no solo impide su participación activa en la protección del mismo, sino que puede conllevar interacciones perjudiciales para los bienes arqueológicos. De hecho, la encuesta recogió que un $84 \%$ de los encuestados ya había buceado en un pecio en alguna ocasión, y un 56\% lo había hecho en un entorno con restos arqueológicos reconocibles. Con los datos recogidos, se trazó un perfil del buceador medio en la zona (figura 6).

Como se puede ver, el polígono de la figura 6 está claramente descompensado: hablamos de un buceador con un nivel alto de interés, que bucea en pecios y zonas con restos arqueológicos, pero no tiene la deseable formación en las directrices éticas de buceo responsable en entornos patrimoniales, ni otros conocimientos recomendables relacionados.

28 Código ético para buceadores acerca de yacimientos arqueológicos sumergidos (UNESCO): http:// www.unesco.org/new/es/culture/themes/underwater-cultural-heritage/partners/diving-community/code-of-ethics/ 


\section{Figura 6 \\ PERFIL DEL BUCEADOR MEDIO}

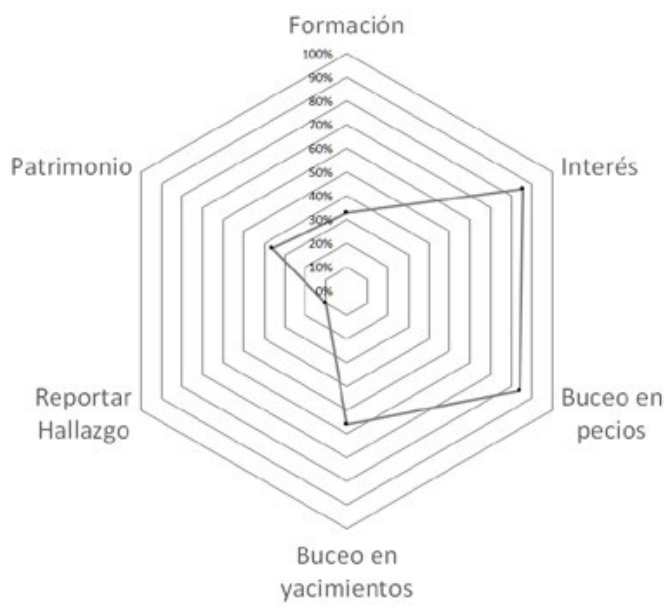

Fuente: Elaboración propia.

Sin embargo, la encuesta también reflejó otros datos positivos: junto al alto grado de interés los buceadores, éstos se mostraban receptivos en un $99 \%$ a recibir más información por parte de sus centros de buceo y un $95 \%$ de ellos creía que este tipo de actividades (de inmersión y formativas) debería realizarse junto con un arqueólogo subacuático.

\subsection{Implantación y desarrollo de la Ruta Arqueológica Subacuática del Bajo de la Campana (Isla Grosa, Murcia) (Julio- Agosto de 2014)}

La ruta se ubicó a los pies del Bajo de la Campana (Isla Grosa) en el yacimiento del pecio fenicio excavado por J. Pinedo y M. Polzer entre los años 2007 y 2011, con la colaboración del INA (Institute of Nautical Archaology) (EEUU) y el Museo ARQVA. La selección de esta zona obedeció a varias razones: condiciones de visibilidad (hasta 14 metros); temperatura (media en torno a unos 21 grados); profundidad (14- 21 metros); relevancia del yacimiento, que es considerado uno de los más importantes en cuanto a cargamento de esta cronología en el Mediterráneo (Mas García, 1985; Roldán Bernal et al.,1995; Ruiz Cabrero y Mederos Martín, 2004; Polzer, 2014; Pinedo Reyes, 2014, 2018); la espectacularidad de la inmersión (a la monumentalidad del bajo se une la riqueza de la vida que lo habita y que se desarrolla en la pradera de posidonia que lo rodea); y, finalmente, la ausencia de material "expoliable": la zona ya había sido excavada y el yacimiento ya había sido publicado por lo que era conocido en la localidad. Se trataba, además, de un punto regular de buceo.

El proceso de implantación de la ruta se inició con una primera fase de coordinación de agentes involucrados (Asociación de Centros de Buceo, Ayuntamientos, Estación Náu- 
tica, instituciones públicas y otras empresas), solicitud de permisos y autorizaciones a las conserjerías pertinentes, y preparación de la actividad subacuática en base al análisis de las necesidades del visitante y de los centros de buceo y a los objetivos educacionales del proyecto. La actividad se planteó desde el origen como una extensión del Museo ARQVA, donde se encuentran los materiales originales de la excavación del yacimiento. Tras la ruta se invitaría a los participantes a visitar dicho museo para, más allá de la museografía, situar estos materiales en un contexto enriquecido gracias a la experiencia.

Las primeras intervenciones para la adecuación del yacimiento y la instalación de los recursos didácticos y señalización subacuática se desarrollaron a lo largo del mes de Junio de 2014. Paralelamente, se diseñó una estrategia de visitas con los centros de buceo interesados, estableciendo un máximo de dos inmersiones diarias al yacimiento en grupos reducidos de 8 buceadores, acompañados en todo momento por un arqueólogo-guía del proyecto y un instructor del centro de buceo visitante. Estos grupos se encargaban de confeccionarlos los propios centros de buceo coordinándose entre ellos y promocionando la experiencia a través de sus canales habituales.

En cuanto a la actividad, antes de la inmersión y todavía en tierra, los buceadores recibían una charla breve por parte del arqueólogo-guía explicándoles qué iban a visitar, la importancia de la Arqueología Subacuática como disciplina de investigación, así como las normas básicas de buceo en pecios y yacimientos arqueológicos elaboradas por la UNESCO. Para ello se utilizaron videos y otros recursos audiovisuales. De forma adicional se diseñaron unos folletos educativos para ponerlos a disposición de los centros de forma permanente.

Terminada la charla formativa, se procedía al embarque. Durante una navegación aproximada de 40 minutos desde el puerto hasta los entornos del Bajo de la Campana, el arqueólogo-guía continuaba su trabajo poniendo en contexto el yacimiento no solo en la Antigüedad sino hasta nuestros días, explicando a los buceadores la riqueza patrimonial de la zona, el significado de la toponimia de los accidentes costeros y, en definitiva, la Historia Marítima del espacio en el que se encontraban y la cultura asociada a ella.

La inmersión guiada se realizaba siguiendo un recorrido (Fig. 7), marcado en el fondo marino con un cabo guía, con paradas preestablecidas. En los puntos de interés se fijaron paneles explicativos con reproducciones de piezas, imágenes de los trabajos o explicaciones de las técnicas de la Arqueología Subacuática. Así, a lo largo de la ruta, el visitante podía ver de dónde y cómo se habían extraído algunos de los objetos expuestos en el museo y, al mismo tiempo, gracias al apoyo de las herramientas interpretativas, conocía la importancia de la Arqueología Subacuática y de la preservación del patrimonio. Dada la ausencia de materiales y con el objetivo didáctico ya mencionado, se recreó fielmente la excavación que se había desarrollado entre los años 2007 y 2011, en sus diferentes fases. De esta manera, durante el recorrido se visitaba la recreación de distintas zonas de excavación, una zona de prospección, podían observarse las diferentes técnicas aplicadas en la metodología arqueológica y, además, se permitía al visitante interactuar con las herramientas propias de esta profesión, comprobando lo ligera que puede ser una manga de succión (desconectada) bajo el agua, o descubriendo los retos del dibujo subacuático (Pérez-Reverte y Cerezo Andreo, 2019). En definitiva, se buscaba ofrecer al visitante una experiencia de relación positiva y responsable con el patrimonio cultural subacuático. 
La inmersión duraba aproximadamente 50 minutos. Una vez terminada, el grupo ascendía a la embarcación y en la navegación de vuelta, tras la experiencia, el arqueólogoguía mantenía con los visitantes una conversación distendida en la que se aclaraban dudas ofreciendo más detalle allí donde se requería. Era realmente en esta navegación de vuelta, tras la visita, cuando los buceadores se mostraban más curiosos y participativos, con preguntas no solo sobre el yacimiento, sino sobre la Historia Marítima, la Arqueología, los pecios y muchas otras cuestiones; donde, desde nuestra perspectiva, se materializaba de forma definitiva esa relación entre el intérprete- intermediario y la sociedad, que consolidaba los objetivos del proyecto. Finalmente, se invitó a los buceadores a visitar el Museo ARQVA y a escribir un email a la dirección del proyecto indicando qué les había parecido la exposición.

\section{Figura 7 \\ CROQUIS DEL RECORRIDO SUBMARINO}
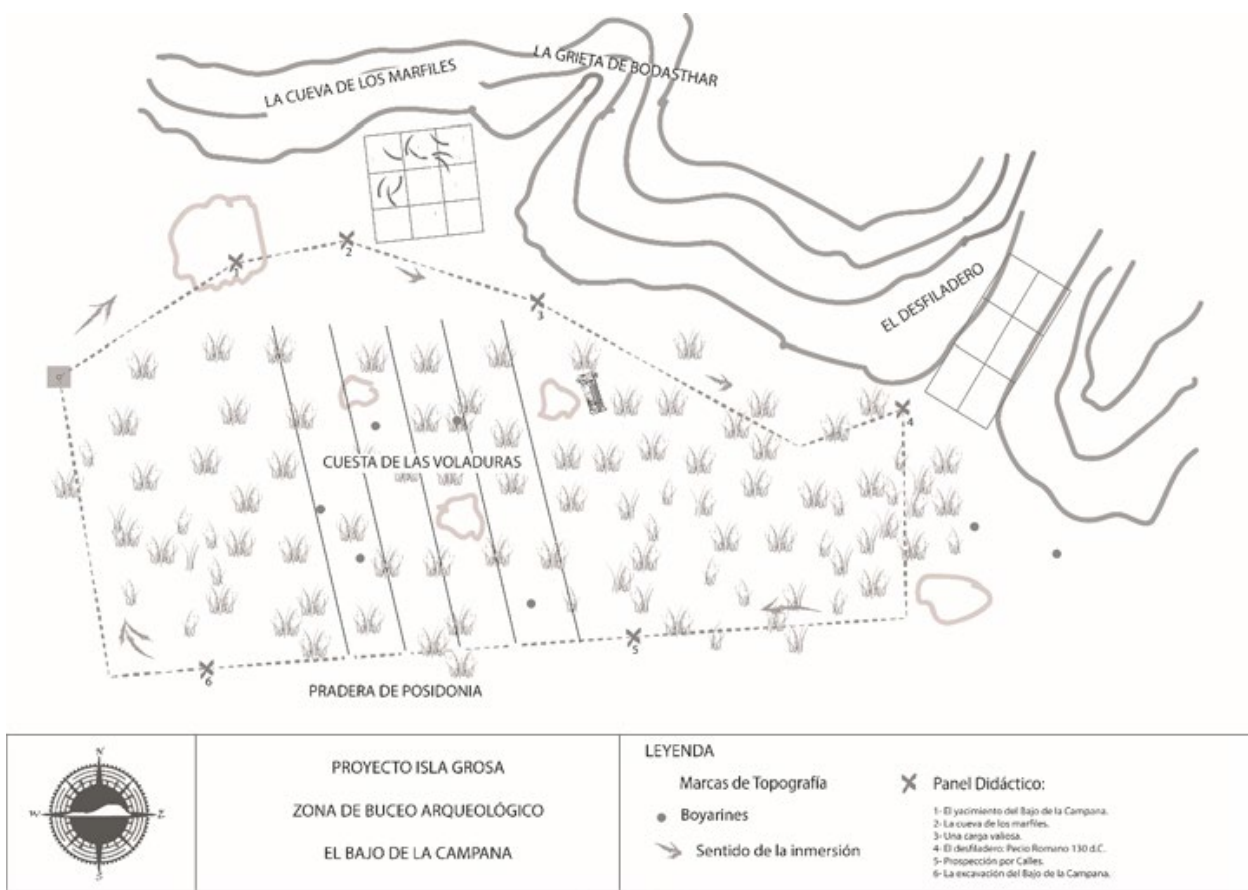

Fuente: Proyecto Isla Grosa.

Un $87 \%$ de los buceadores visitó en los días siguientes el Museo ARQVA. El feedback de estos correos electrónicos fue muy positivo; los materiales se situaron en un contexto unitario pese a estar en diferentes vitrinas y se observó una suerte de apropiación e individualización de las piezas. Para los visitantes, dejaron de ser objetos arqueológicos "genéricos" para convertirse en objetos arqueológicos "específicos": los conocían (y por tanto 
los reconocían), conocían su origen, sus peculiaridades, su historia individual y colectiva. Se habían apropiado de su valor cultural y patrimonial.

Con el objetivo de ampliar el retorno social del proyecto, durante todo el verano de 2014 se desarrollaron actividades complementarias para no buceadores tales como talleres infantiles, visitas guiadas en tierra y charlas informativas en diferentes hoteles y centros culturales.

\section{CONCLUSIONES}

La Región de Murcia ha diversificado su oferta cultural de forma significativa en los últimos años. En este proceso, tanto el patrimonio como el mar han sido dos de sus puntos estratégicos. Sin embargo, no de forma conjunta. Pese a la riqueza de su Historia y su larga tradición cultural marítima, la mayor parte de iniciativas desarrolladas en este sentido han surgido de agentes privados en función de sus intereses, posibilidades y limitaciones, detectándose un vacío importante en el ámbito público, más allá de la difusión tradicional que se realiza en museos como el Nacional de Arqueología Subacuática (ARQVA), el centro de interpretación del barco fenicio de Mazarrón o algunas salas expositivas de museos locales.

La zona de La Manga-Mar Menor, pese a ser una de las regiones que más ha sufrido el impacto del modelo turístico residencial y masificado, ha visto potenciada su oferta solo en relación con el mar como espacio de ocio y deporte, quedando su patrimonio relegado a un segundo plano, si no olvidado por completo. Aunque en la actualidad se encuentra activo un "turismo de pecios", no puede considerarse un tipo de turismo cultural puesto que no implica una puesta en valor real y la información que reciben los buceadores, su interacción con los pecios y el proceso de interpretación quedan a discreción de los centros de buceo.

El Proyecto Isla Grosa se gestó con el doble propósito de educar y concienciar a los buceadores y a la comunidad local en general, y colaborar con los centros de buceo en la generación de una experiencia completa para el buceador que permitiera disfrutar del patrimonio de manera responsable. Pese a no contar con restos arqueológicos visibles, la experiencia fue valorada de forma extremadamente positiva por los visitantes. Esto demuestra la importancia de un adecuado proceso de interpretación y de una planificación adecuada.

Por otra parte, el proyecto se planteó con la intención de involucrar a diferentes sectores y agentes locales, y contó con la participación variada de empresas, asociaciones, universidades, ayuntamientos y otras entidades, demostrando que hay un interés genuino por facilitar y promover estas líneas de trabajo en la comunidad local y en la propia Región.

En este sentido, la educación es un factor fundamental puesto que la fragilidad del patrimonio cultural subacuático requiere condiciones especiales para su puesta en valor. Pese al interés que pueden generar los restos sumergidos, es importante recordar que hacer los yacimientos visitables no siempre es posible. Conocer y comprender las especificidades de estos bienes y la problemática asociada, es fundamental a la hora de plantear los objetivos y estrategias para desarrollar su investigación, garantizar su conservación y promover su difusión. Por otra parte, la difusión, la visibilidad y la viabilidad económica son también mecanismos de protección y supervivencia. Con el fin de poner en valor la cultura marítima de la Región y proteger, preservar y difundir el patrimonio asociado a ella (del que los pecios y otros restos materiales sumergidos son sólo una pequeña parte), se hace necesaria la colaboración entre los diferentes especialistas en ese binomio patrimonio-turismo. 
Como se ha podido ver, la zona de La Manga-Mar Menor tiene una gran potencialidad con restos y yacimientos de diferentes épocas tanto en el medio terrestre como subacuático. La puesta en valor de este patrimonio y de la cultura marítima que le da contexto, podría servir no solo para diversificar la oferta turística sino, también, para potenciar la protección y pervivencia de estos fragmentos de Historia.

Si durante buena parte de la Edad Moderna, el mar y lo que representaba fue concebido como un peligro en esta zona geográfica, algo tabú, un espacio de piratería, esclavitud y muerte, ahora es una oportunidad para el desarrollo, pero también para una educación y puesta en valor sostenible de una parte de nuestra Historia.

\section{AGRADECIMIENTOS}

Este es un trabajo en el que han participado múltiples actores, coordinados por la Asociación de Amigos del Museo Nacional de Arqueología Subacuática ARQVA. Agradecemos el mecenazgo de la Fundación CajaMurcia y Enagás, y la colaboración de otras instituciones y entidades entre las que nos gustaría mencionar la Estación Náutica Mar Menor, el Puerto Tomás Maestre, la Asociación de Naturalistas del Sureste (ANSE), Grupo El Ciruelo, la Asociación de Amigos de los Museos de San Pedro del Pinatar y, especialmente, la Asociación de Centros de Buceo de la Región de Murcia. Finalmente, quedamos muy agradecidos al editor y revisores de este trabajo por sus comentarios y sugerencias, que han mejorado la versión preliminar.

\section{BIBLIOGRAFÍA}

ABATINO, E. (1985): «Il Parco Naturale di santa María di Castellabate. In Ente Provinciale per il Turismo di Salerno», en I Parchi costieri mediterranei. Atti del Convegno Internazionale, Salerno-Castellabate, 18-22 giugnio 1973, pp. 29-45.

AGUILAR, C. (2011): «La participación de las federaciones deportivas de buceo en la protección del patrimonio arqueológico subacuático: proyectos y experiencias de cooperación entre FECDAS/CMAS y CASC-MAC», en Actas de las IV Jornadas de Jóvenes en Investigación Arqueológica. Faro, 11-14 mayo de 2011, vol. II, pp. 41-48

AGUIZZA, S. (2012): "The marine protected area of S. Maria di Castellabate and the archaeological "site" of Licosa», en Actas de las IV Jornadas de Jóvenes en Investigación Arqueológica. Faro, 11-14 mayo de 2011, pp. 65-71.

BALLART, J. (2010): El patrimonio histórico y arqueológico: valor y uso. Barcelona, Ariel.

BELLIDO BLANCO, A. (2018) «El patrimonio cultural no es eterno», Revista PH. Instituto Andaluz de Patrimonio Histórico, $\mathrm{n}^{\circ}$ 93, pp. 156-157.

BOMBICO, S; ABELLÁ, D.; CEREZO ANDREO, F. (2013): «El Patrimonio Cultural Subacuático, un tesoro de todos y para todos. Arqueología Subacuática y participación social en la protección del PCS», en Actas de las V Jornadas de Jóvenes en Investigación Arqueológica. Arqueología para el siglo XXI. Santiago de Compostela, mayo de 2012, pp. 236-238. 
CATSAMBIS, A. y MORRAND, K. (2015): «Connecting the Wrecks: A Case of Study in Conveying the Importance of Submerged Cultural Heritage Through a Scaled Outreach Approach», en JAMESON, J. H. y SCOTT-IRETON, D. A. (Eds.): Out of the Blue. Nueva York, Springer, pp. 11-25.

CEBRIÁN ABELLÁN, A. (2004): «Políticas institucionales y turismo cultural. El ejemplo de la Región de Murcia», Cuadernos de Turismo, n 13, pp. 7-25.

CEEIC (2016): Estudio de oportunidades de negocio en el sector de actividades subacuáticas en la Región de Murcia. Disponible en:

http://prometeoemprende.es/wp-content/uploads/2017/04/INFORME-OP.-NEGOCIOBUCEO-vDEF.pdf

CEREZO ANDREO, F. (2012): «La Convención de la UNESCO sobre la Protección del Patrimonio Cultural Subacuático 2001. Las nuevas vías de trabajo en el campo de la Arqueología Subacuática y su Difusión», en Actas de las IV Jornadas de Jóvenes en Investigación Arqueológica. Faro, 11-14 mayo de 2011, vol II, pp. 37-40.

CERRILlOS, M.L. (2014): «¿De quién es el patrimonio?» [Ponencia], en El silencio de los ídolos. Una evocación de la estatuaria agustiniana, 20 de febrero de 2014, Auditorio Teresa Cuervo Borda del Museo Nacional de Colombia. Disponible en: https:// www.youtube.com/watch?v=fU81X69_4lY

DAVIDDE, B. (2002): «Underwater archaeological parks: a new perspective and a challenge for conservation-the Italian panorama», The International Journal of Nautical Archaeology, vol. 31 (1), pp. 83-88.

FERNÁNDEZ IBÁÑEZ, C. y PALACIO RAMOS, R. (2003): «Introducción», Monte Buciero, $\mathrm{n}^{\circ}$ 9: La conservación del Material Arqueológico Subacuático, pp. 11-14.

FUENTES, M. C. (2015): «Patrimonio y turismo cultural (Primera parte)», en NEGRO, S. (Comp.): Reflexiones en torno al patrimonio cultural del Perú. Lima, Universidad Ricardo Palma, pp. 9-20.

GARCÍA CANO, C. (1996): «Informe sobre el poblado ibérico de La Loma del Escorial, Los Nietos, (Cartagena)», Memorias de Arqueología de la Región de Murcia, $\mathrm{n}^{\circ} 5$, pp. 127-140.

GONZÁLEZ DÍAZ, J.V. (2017): Una inmersión en la Historia. Parque Arqueológico Subacuático vinculado a la batalla naval de Santiago de Cuba. Sevilla, Escandón Impresores.

HERRERO PRIETO, L.C. y DEVESA FERNÁNDEZ, M. (2012): «La cultura y el turismo como factores de desarrollo de la economía de Valladolid», en FERNÁNDEZ ARUFE, J.E., OGANDO CANABAL, J.O. y JUSTE CARRIÓN, J.J. (Eds.) La Economía de la provincia de Valladolid. Almería, Servicio de Estudios de la Fundación Cajamar, pp. 405-435.

HOFFMANN, D.L., ANGELUCCI, D.E., VILLAVERDE, V., ZAPATA, J. y ZILHÃO, J. (2018): «Symbolic use of marine shells and mineral pigments by Iberian Neandertals 115,000 years ago», Science Advances, vol. 4 (2), eaar5255.

INIESTA SANMARTÍN, A. (2008): «El Patrimonio Cultural Inmaterial de la Región de Murcia. Algunas reflexiones sobre su papel en la visión del patrimonio cultural como factor de cooperación interregional, desarrollo social y sostenibilidad económica», en 
GARCÍA SIMÓ (Coord.) El patrimonio cultural inmaterial. Definición y sistemas de catalogación. Actas del Seminario Internacional. Murcia, 15 y 16 de febrero de 2007. Murcia, Dirección General de Bellas Artes y Bienes Culturales, pp.53-59

KHAKZAD, S. y VAN BALEN, K. (2012): «Complications and effectiveness of In Situ Preservation Methods for Underwater Cultural Heritage», Conservation Management of Archaeological Sites, vol. 14 (1-4), pp. 469-478.

LEMA CAMPILLO, A. (2008): «La gestión del patrimonio inmaterial en sociedades complejas en el siglo XXI. Propuestas para implementar políticas de actuación en la Región de Murcia, España», en GARCÍA SIMÓ (Coord.) El patrimonio cultural inmaterial. Definición y sistemas de catalogación. Actas del Seminario Internacional. Murcia, 15 y 16 de febrero de 2007. Murcia, Dirección General de Bellas Artes y Bienes Culturales, pp. 71-84.

LLULL PEÑALBA, J. (2005): «Evolución del concepto y de la significación social del patrimonio cultural», Arte, Individuo y Sociedad, vol. 17, pp. 175-204.

MARTÍN GUGLIELMINO, M. (2007) «La difusión del patrimonio. Actualización y debate», E-rph, Revista electrónica de Patrimonio Histórico, no 1, pp. 195-216.

MAARLEVELD, T.J., GUÉRIN, U. y EGGER, B. (2013): Manual para actividades dirigidas al Patrimonio Cultural Subacuático. París.

MAZÓN MARTÍNEZ, T. y ALEDO TUR, A. (2005): «El dilema del turismo residencial: ¿turismo o desarrollo inmobiliario?», en MAZÓN MARTÍNEZ, T. y ALEDO TUR, A. (Coords.): Turismo Residencial y Cambio Social. Nuevas Perspectivas Teóricas $Y$ Empíricas. Alicante, Universidad de Alicante, pp. 13-30.

MARCOS PÉREZ, D. y GONZÁLEZ VELASCO, D.J. (2003): Turismo accesible. Madrid, Comité Español de Representantes de Personas con Discapacidad (CERMI), Disponible en:

http://www.accesturismo.com/assets/img/publicaciones-02/Turismo_Accesible.pdf

MARTÍNEZ ANDREU, M. (2003): «Nuevas propuestas para el estudio de las sociedades cazadoras-recolectoras en el suroeste peninsular», en Estudios de arqueología dedicados a la profesora Ana María Muñoz Amilibia. Murcia, Universidad de Murcia, pp. 145-154.

MÁS GARCÍA, J. (1985): «El polígono submarino de Cabo de Palos: sus aportaciones al estudio del tráfico marítimo antiguo», en Actas del VI Congreso Internacional de Arqueología Submarina. Cartagena, Ministerio de Cultura, pp. 153-174.

turismo residencial:; turismo o desarrollo inmobiliario?." Turismo residencial y cambio social: nuevas perspectivas teóricas y empíricas. (pp: 13-30) Universidad de Alicante, 2005.

MCKINNON, J.F. y CARRELL, T. (2011): Saipan WWII Invasion Beaches Underwater Heritage Trail. Washington, American Battlefield Protection Program.

MILLÁN ESCRICHE, M. (2001): «Viejos recursos para nuevos turismos: el caso de la Región de Murcia», Cuadernos de Turismo, no 8, pp. 109-128.

MONTES, R. (1991): «La Cueva de los Aviones. Un yacimiento del Paleolítico Medio (Cartagena, Spain)», en Memorias de Arqueología de la Región de Murcia, $\mathrm{n}^{\circ} 2$, pp. 35-38 
MORAGUES CORTADA, D. (2006): Turismo, cultura y desarrollo. Madrid, Agencia Española de Cooperación Internacional.

MORALES YAGO, F.J. (2013): «El impacto de la actividad turística sobre el paisaje de La Manga del Mar Menor (Murcia)», Estudios Geográficos, n 275, pp. 523-556.

MUNUERA NAVARRO, D. (2010): Musulmanes y cristianos en el Mediterráneo. La costa del Sureste Peninsular durante la Edad Media (ss. VIII-XVI). Murcia, Universidad de Murcia.

NEGUERUELA, I., PINEDO, J., GÓMEZ, M., MIÑANO, A., ARELLAO, I. y BARBA, J.S. (1995): «Seventh-century BC Phoenician vessel discovered at Playa de la Isla, Mazarrón, Spain», International Journal of Nautical Archaeology, vol. 24 (3), pp. 189-197.

NIETO, X. (2007): «Problemática de la visita pública a los yacimientos arqueológicos subacuáticos. El caso del Puerto de Ampurias», Comunicare la memoria del Mediterraneo (ANSER), pp.125-130.

ORDUNA, G. y URPÍ, C. (2010): «Turismo cultural como experiencia educativa de Ocio», en Polis, $\mathrm{n}^{\circ}$ 26, p. 4. Disponible en: http://polis.revues.org/102

PÉREZ-PRAT DURBÁN, L. (2014): «Observaciones sobre el derecho al patrimonio cultural como derecho humano», Periférica: Revista para el análisis de la cultura y el terrorismo, $\mathrm{n}^{\circ} 15$, pp. 319-342.

PÉREZ-REVERTE, C. y CEREZO ANDREO, F. (2019): «De la extracción a la puesta en valor de los pecios históricos. Evolución conceptual de la puesta en valor de los hallazgos subacuáticos: un caso práctico, el proyecto "Isla Grosa", en La recuperación del patrimonio arqueológico sumergido: problemas y propuestas: Phicaria, VII Encuentros Internacionales del Mediterráneo. Mazarrón, Universidad Popular de Mazarrón, pp. 105-122.

PINEDO REYES, J. (1996): "Inventario de yacimientos arqueológicos subacuáticos del litoral murciano», Cuadernos de Arqueología Marítima, nº 4, pp. 57-90.

PINEDO REYES, J. (2014): «Investigaciones arqueológicas subacuáticas en el Bajo de la Campana 2007-2011 San Javier (Murcia)», en Arqueología subacuática española: Actas del I Congreso de Arqueología Naútica y Subacuática Española, Cartagena, 14, 15 y 16 de marzo de 2013. Cádiz, Universidad de Cádiz, vol. 1, pp. 27-34.

PINEDO REYES, J. (2018): «Comercio fenicio a través de los datos proporcionados por el yacimiento subacuático del Bajo de la Campana: estudio preliminar», en Navegar el Mediterráneo: Phicaria, VI Encuentros Internacionales del Mediterráneo, pp. 99-116. POLZER, M. (2014): «The Bajo de la Campana Shipwreck and Colonial Trade in Phoenician Spain», en ARUZ, J.; GRAFF, S.B. y RAKIL, Y. (Eds.): Assyria to Iberia at the Dawn of the Classical Age, Nueva York, Met. Publications.

QUEROL, M.A. y MARTINEZ, B. (1996): La gestión del Patrimonio Arqueológico en España. Madrid, Alianza Universidad.

ROLDÁN BERNAL, B., MIÑANO DOMÍNGUEZ, A. y MARTÍN CAMINO, M. (1995):

«El yacimiento arqueológico subacuático de El Bajo de la Campana», en Actas del XXI Congreso Nacional de Arqueología, 3, pp. 965-974. 
RUIZ CABRERO, L.A. y MEDEROS MARTÍN, A. (2004): «El pecio fenicio del Bajo de la Campana (Murcia, España) y el comercio del marfil norteafricano», Zephyrus: Revista de Prehistoria y Arqueología, no 57, pp. 263-281.

SALVÁ TOMÁS, P.A. (1998): «Los modelos de desarrollo turístico en el Mediterráneo», Cuadernos de Turismo, $\mathrm{n}^{\circ}$ 2, pp. 7-24.

SCOTT-IRETON, D.A. (2006): «Florida's Underwater Archaeological Preserves: Preservation through Education», en GRENIER, R.; NUTLEY, D.; COCHRAN, I. (Eds.): ICOMOS Heritage at Risk Special Edition. Underwater Heritage at Risk: Managing Natural and Human Impacts, pp. 5-7

SCOTT-IRETON, D.A. (2007): «The Value of Public Education and Interpretation in Submerged Cultural Resource Management», en JAMESON, J. H.; SCOTT-IRETON, D. A. (Eds.): Out of the Blue. Nueva York, Springer, pp. 19-32.

SIERRA MÉNDEZ, J.L. (2003): «La conservación de la madera en arqueología subacuática. Museo y Centro Nacional de Investigaciones Arqueológicas Submarinas», Monte Buciero, $\mathrm{n}^{\circ}$ 9: La conservación del Material Arqueológico Subacuático, pp. 226-266.

STANIFORTH, M. (2010): «Issues in Education in Maritime Archaeology», en AMOEDA, L. y PINHEIRO, C. (Eds.): Heritage 2010: Heritage and Sustainable Development. Evora, Greenlines Institute for Sustainable Development, pp. 315-322.

STEFANILE, M. (2012): «Baia, Portus Julius and surroundings. Diving in the Underwater Cultural heritage in the Bay of Naples (Italy)», en ONIZ, H.; CICEK, B. (Eds.) Proceedings of the 6th International Symposium on Underwater Research-Antalya-Kemer 2012 , pp. 28-47

TORRES FONTES, J. (1987): «La pesca en el litoral murciano durante la Edad Media», en Nuestra Historia. Aportaciones al Curso de Historia sobre la Región de Murcia. Cartagena, Ayuntamiento de Cartagena, pp. 113-127.

TOSELLI, C. (2006): «Algunas reflexiones sobre el turismo cultural», Pasos. Revista de Turismo y Patrimonio Cultural, vol. 4 (2), pp. 175-182. 